\title{
Chemical Communication
}

\section{COMMUNICATION}

\section{Surface Confined Self-Assembly of Polyampholytes Generated from Charge-Shifting Polyelectrolytes}

Received 00th January 20xx, Accepted 00th January 20xx

DOI: $10.1039 / \times 0 \times x 00000 x$

\author{
T. Garniert, ${ }^{a}$ A. Dochtert, ${ }^{b}$ and N. T. T. Chau, ${ }^{a}$ P. Schaaf, ${ }^{a, b, c, d, e, f *}$ L. Jierry, ${ }^{a, d, f}$ and F. \\ Boulmedais ${ }^{\mathrm{a}, \mathrm{d}, \mathrm{f} *}$
}

www.rsc.org/

Polyampholyte-based films can be efficiently self-assembled onto a surface in a one-pot manner. By using a gradient of protons generated at an electrode surface, a charge-shifting polyelectrolyte present in solution can be transformed into a polyampholyte, leading to the continuous buildup of a film based on electrostatic interactions.

Polyelectrolyte multilayers constitute a very powerful and versatile tool allowing the functionalization of almost any kind of substrate, whatever its chemical nature and morphology. ${ }^{1}$ Obtained by the alternate deposition of polyanions and polycations on a surface, they rely on electrostatic interactions between positive and negative charges and can be considered as polyanion/polycation complex assemblies. Because of this alternation between positive and negative charges, polyelectrolyte multilayers necessitate, by essence, the use of two oppositely charged polyelectrolytes. Recently, it was however reported that one can also buildup, in a step-by-step manner, films from a single solution containing polycation/polyanion complexes, PEDOT/PSS respectively (PEDOT: poly(3,4-ethylenedioxythiophene); PSS: poly(styrene sulfonate)). ${ }^{2}$ Yet, this film was obtained by a step-by-step adsorption of each layer of PEDOT/PSS realized by spin-coating and followed by a drying step after each deposition. Powerful and versatile, the layer-by-layer technology suffers from some drawbacks. One of them is that the buildup process can be long and tedious when an important number of deposition steps is required.

It is thus of interest to develop alternative buildup strategies, in particular one-pot strategies which are by far more rapid and convenient. Caruso and Qiao have recently developed a concept moving in this direction based on the Continuous Assembly of Polymers (CAP) through sequential and chemical cross-linking steps. ${ }^{3}$ Yet, the main question is, how to obtain a single solution

\footnotetext{
a. Institut Charles Sadron (UPR22-CNRS), 23 rue du Loess, BP 84047, 67034, Strasbourg Cedex 2, France.

b.INSERM, UMR-S 1121, 11 rue Humann, 67085 Strasbourg Cedex, France. c. Université de Strasbourg, Faculté de Chirurgie Dentaire, 8 rue Sainte Elisabeth, 67000 , Strasbourg, France.

d. icFRC, 8 allée Gaspard Monge, 67083 Strasbourg, France.

e. IUF, 103 boulevard Saint-Michel, 75005 Paris, France.

f. USIAS, 5 allée du Général Rouvillois, 67083 Strasbourg, France.

+ Both authors contributed equally.

Electronic Supplementary Information (ESI) available: [NMR monitoring, XPS analysis, AFM images, experimental set-ups]. See DOI: 10.1039/x0xx00000x
}

with constituents that will not interact together but interact exclusively near the interface leading to a one-pot film buildup? The answer can come from a biomimetic inspiration, by simply having a look on how nature initiates and creates complex three dimensional morphologies at one pole of an undifferentiated cell during embryogenesis using morphogens. ${ }^{4}$ Morphogens can be defined as chemical species that are generated locally, diffuse into solution, through tissues and affect cell fate. In 2011, our group has introduced a new strategy to build, in a one-pot manner, thin films made of polymers of same charge but covalently linked by the azide/alkyne click reaction. This reaction is catalysed by $\mathrm{Cu}(\mathrm{I})$, electrochemically generated in situ at an electrode, playing the role of morphogen. ${ }^{5}$ This approach of film buildup has been actively developed so far by our group ${ }^{6}$ and the community. ${ }^{7}$ But without formalising it, the morphogen approach is used since a long time in car industry to produce anti-corrosion surfaces. Generated electrochemically, protons, i.e. morphogens, diffuse into the solution and interact with polymers rendering them insoluble. ${ }^{8}$ Electro-precipitation induced by $\mathrm{pH}$ changes has been largely exploited by the group of Payne who developed films based on chitosan, a polysaccharide known to become insoluble in water above $\mathrm{pH}$ 6.5. ${ }^{9}$
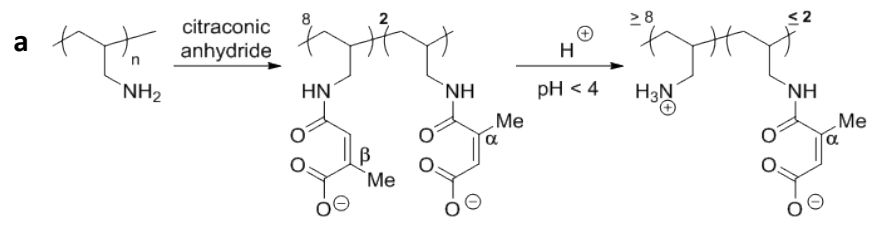

Poly(allylamine) PAHc Partially hydrolyzed PAHc:

b

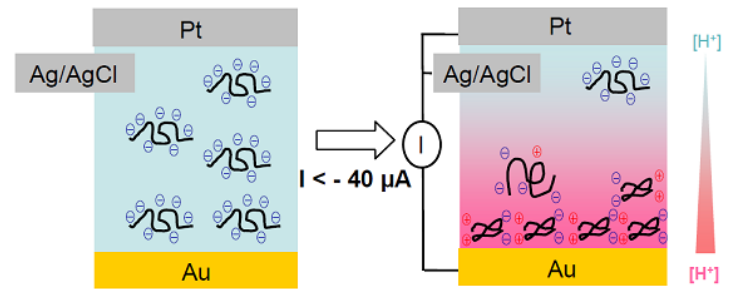

Fig. 1: (a) Nucleophilic addition of amino groups from PAH with citraconic anhydride. Two isomers derived-citraconate in ratio 2/8 are present along the polymer backbone of PAHc (b) Schematic representation of electrochemically triggered morphogen driven surface confined self-assembly of polyampholytes based on charge-shifting polyelectrolyte. 
Herein, we demonstrate that this concept can be extended one step further to obtain a one pot buildup of films made from only one polyelectrolyte. By using citraconate-modified poly (allylamine hydrochloride) (PAHc), a partially charge shifting polyelectrolyte, it is possible to generate in situ a polyampholyte (Fig. 1a). This polymer can self-assembled on himself due to charge complexation leading to a polyampholyte-based film. This original approach can be considered as the ultimate simplified polymer system leading to a one-pot film deposition based on electrostatic interactions.

In 2008, Lynn and coworkers have designed and prepared the PAHc and used it to build multilayer films in a step-by-step manner. ${ }^{10}$ The hydrolysis property of the PAHc allows a gradual erosion of the multilayer over time, depending on the $\mathrm{pH}$ in the media. This elegan strategy has been used to control the release of biological compounds due to the degradation of the film. Amide bonds hydrolysis in aqueous solution is not a chemical reaction that occurs rapidly. However, maleic amide derivatives do not respect this rule. Indeed, this class of amide bonds is used to be cleaved easily at low $\mathrm{pH}$ providing free amino groups. ${ }^{10}$ The explanation of its ability of hydrolysis lies in the presence of a carboxylic groups close to the amide bond. ${ }^{11}$ It must be noted that the PAHc has two isomers of citraconic acid groups grafted along the polymer backbone: one with the methyl group in $\alpha$ position (proximal) and the second one in $\beta$ position (distal). The $\alpha / \beta$ ratio is $2 / 8$ and can be explained by the easier nucleophilic addition of the free amine of the PAH onto the less hindered carbonyl group of the citraconic anhydride during the synthesis of PAHc (Fig. 1a). The hydrolysis behaviour of PAHc was monitored by ${ }^{1} \mathrm{H}$ NMR through the integration of vinyl signals of both isomers $\alpha$ and $\beta$ at acidic $\mathrm{pD}$ $(\mathrm{pD}=\mathrm{pH}+0.41) .{ }^{12}$ When dissolved in deuterated water at $\mathrm{pD} 5.89$, a partial hydrolysis of the major isomer, having the methyl group in $\beta$ position, occurs slowly until a complete conversion after 2 days when the minor one is not affected (Fig. S1 in Electronic Supplementary Information, ESI). When the $\mathrm{pD}$ is at 4.18 , the major isomer is fully hydrolyzed in less than ten minutes. This leads to more than $80 \%$ of hydrolysis of PAHc (i.e. $18 \%$ of remaining isomers). A polyampholyte polymer containing more than $80 \%$ of positive charges is thus obtained. More than $4 \mathrm{~h}$ at $\mathrm{pD} 4.18$ are required to transform entirely $\mathrm{PAHc}$ in PAH. This results are in accordance with the literature. $^{13}$ Therefore, it seems possible to create in situ a polyampholyte in solution at $\mathrm{pH}<5$ from $\mathrm{PAHc}$ due to the simultaneous presence of positive and negative charges along the same polymer chain (Fig.1a). Going one step further, if a sufficient gradient of protons is generated from a surface (an electrode) in the presence of PAHc in solution, the polyampholyte derived from the partial PAHc hydrolysis may self-assemble on himself. This could lead to a polyelectrolyte film based on the solely electrostatic interaction coming from only one polyelectrolyte. This idea constitutes the core strategy for the design of a surface-initiated film construction driven by morphogens (protons, generated from the surface). Several methods are described to create a gradient of protons from an electrode. By electrochemical oxidation of hydroquinone into 1,4-benzoquinone, two electrons are transferred to the electrode concomitantly with the production of two protons released in the media. Compared to the electrolysis of water which is another common way to generate protons, the oxidation of hydroquinone allows working with a lower oxidative potential, roughly $0.3-0.4 \mathrm{~V}$ and therefore is convenient with the use of gold-coated working electrode. By oxidizing hydroquinone at an electrode, a $\mathrm{pH}$ of 3.6 has been calculated in the close vicinity of the surface that increases gradually to neutral away from it. ${ }^{14}$
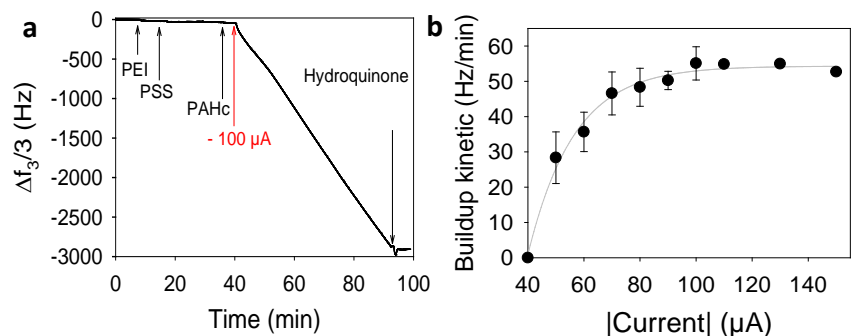

Fig. 2: (a) Evolution of the normalized frequency shift, $\Delta f_{3} / 3$, as a function of time at an applied current of $-100 \mu \mathrm{A}$ of PAHc solution in the presence of 60 $\mathrm{mM}$ of hydroquinone in contact with a PEI-PSS pre-coated electrode (b) Evolution of the buildup kinetic, slope of the normalized frequency shift vs time, as a function of the applied current intensity. The data represent the mean and the standard deviation of three independent experiments.

The self-construction of films was monitored by an electrochemical quartz crystal microbalance (EC-QCM) during the application of a controlled current intensity on the gold electrode of the QCM substrate. The film buildup was performed under a slight flux $(0.05 \mathrm{ml} / \mathrm{min})$ to ensure a constant concentration of reactants. The gradient of morphogens, the protons, was created by electrochemical oxidation of hydroquinone induced galvanostatically from the electrode surface by applying oxidation currents. All experimental details are given in ESI. Fig. 2a shows the evolution of the frequency shift for the third overtone $\left(\Delta f_{3} / 3\right)$ depending on the different adsorption steps realized on the gold substrate. The electrode was first covered with a layer of branched poly(ethylenimine) (PEI) to ensure a strong anchoring on the surface followed by the deposition of a PSS layer rendering the surface negatively charged. PEI-PSS bilayer leads to a decrease of $50 \mathrm{~Hz}$ of the frequency shift. PAHc solution (1 $\mathrm{mg} / \mathrm{mL}$ ), containing $60 \mathrm{mM}$ of hydroquinone at $\mathrm{pH} 6$, is introduced in the QCM cell. No significant evolution of the frequency shift is observed. As soon as a constant current of $-100 \mu \mathrm{A}$ is applied through the electrode, a linear decrease of the frequency shift takes place. After $1 \mathrm{~h}$ at an applied current of $-100 \mu \mathrm{A}$, a rinsing step can be applied with $150 \mathrm{mM} \mathrm{NaNO} 3$ solution containing $60 \mathrm{mM}$ of hydroquinone while maintaining the current. The frequency shift remains constant, the film growth is thus stopped (Fig. 2a). If the film is rinsed without the application of the current or without the presence hydroquinone, an increase of the frequency shift takes place which returns almost to the initial value before the film buildup (data not shown). In the absence of current and thus of $\mathrm{pH}$ gradient, the film does not remain stable. It might be due to the fact that when the current is stopped, the $\mathrm{pH}$ inside the film is changed. Modifying the protonation of the amine and carboxylic groups (from citraconate moieties) along the polymer chains, the anionic/cationic equilibrium is affected leading to a destabilization of the film cohesion. The buildup kinetic of the polyampholyte film can be determined by calculating the slope of the normalized frequency shift versus time during the application of the current (Fig. 2b). The faster film buildup is obtained when the intensity applied is lower or equal to $-100 \mu \mathrm{A}$. After $3 \mathrm{~h}$ at an applied current of $-100 \mu \mathrm{A}$, the buildup of the film suddenly levels off during $1 \mathrm{~h}$ and the frequency shift then increases rapidly to reach its value observed before current application (Fig. S2 in ESI). The film is no longer stable and dissolves in solution. This is expected from the full PAHc hydrolysis process leading to the polycation, PAH. This observation is in agreement with ${ }^{1} \mathrm{H}$ NMR study (Section 1 in ESI). 

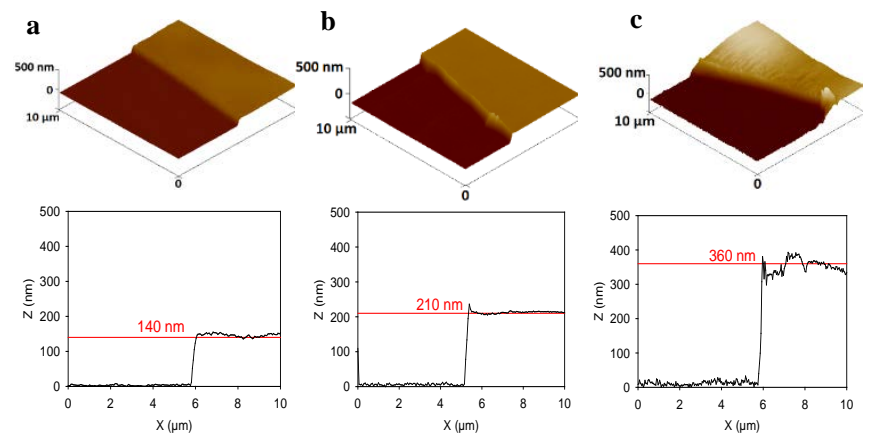

Fig. 3: Typical 3D AFM images, obtained in contact mode and dry state, and its profilometric sections $\left(10 \times 10 \mu \mathrm{m}^{2}\right)$ of polyampholyte films obtained at an applied current of $-100 \mu \mathrm{A}$ after (a) 30, (b) 45 and (c) 60 min of application time. These films were built on a EC-QCM quartz crystal. The zero-value line in $\mathrm{Z}$ is arbitrarily defined by the apparatus.

The topography of the films was studied by AFM in dry condition by using the contact mode. The film growth was stopped after 30, 45 and 60 min of buildup at an applied current of $-100 \mu \mathrm{A}$. The filmcoated crystal was removed from the QCM cell, dried with a stream of nitrogen and imaged. A scratch of the film was performed in order to get its thickness (Fig. 3). The film is extremely smooth and growth linearly with time to reach $360 \mathrm{~nm}$. Fig. S3 (ESI) shows the evolution of the polyampholyte films thicknesses and roughnesses obtained at an applied current ranging from -50 to $-100 \mu \mathrm{A}$ for $1 \mathrm{~h}$. For the same time of buildup, lower applied intensities lead to thicker films. Moreover, the film thickness linearly correlates to the intensity applied to build the film.

In situ composition of the film prepared by applying a current of $-100 \mu \mathrm{A}$ was determined by XPS after 30, 45 and 60 min of film buildup (Section 2 in ESI). This analysis allows the measurement of amino $\left(\mathrm{NH}_{2}\right)$ and ammonium $\left(\mathrm{NH}_{3}{ }^{+}\right)$group proportions along the partially hydrolysed PAHc backbone through the detection of nitrogen atoms. The nitrogen involved in the citraconamide bond (NHCO) is also measurable. Evolution of the ratio between the proportion of the citraconamide group (NHCO) and all nitrogen-containing groups (N1s), NHCO/N1s, allows to determine the degree of hydrolysis of PAHc that composed the film. After $30 \mathrm{~min}, 63 \%$ of the PAHc has been hydrolysed (ratio NHCO/N1s= 0.36 ), going to $73 \%$ of hydrolysis measured both at 45 and 60 min of construction (ratio NHCO/N1s= 0.27 in both cases). The PAHc seems to be hydrolysed partially and rapidly in the first minutes of the film buildup, going to a plateau close to $73 \%$ (Fig. S4 in ESI). This value of hydrolysis is in agreement with the ${ }^{1} \mathrm{H}$ NMR study performed in solution at $\mathrm{pD}$ 4.18: the $\beta$ isomer (80\%) present all along the PAHc is quickly hydrolysed, leaving the pH-insensitive citraconamide $\alpha$ isomer (20\%) anchored onto the polymer backbone. This XPS analysis confirms the polyampholyte nature of the constituting polymer of the film. Furthermore, it validates our buildup strategy based on the chemical transformation of a polyelectrolyte into a polyampholyte, leading to a film buildup.

To avoid the dissolution of polyampholyte-based films in contact with an aqueous solution, they were chemically crosslinked by a heating treatment at $150^{\circ} \mathrm{C}$ for $12 \mathrm{~h}$. Stable amide bonds are formed by reaction between amine and carboxylic groups ${ }^{15}$ both presents along the hydrolysed PAHc. After the thermal crosslinking, the polyampholyte based film thickness decreases by half of its initial value. In contact with water, the thickness remains constant even after two cycles of drying-hydrating steps, indicating that the crosslinking provided a robust architecture (Fig. S5 in ESI).
Morphogen-driven film buildup is herein illustrated by a new way of polyelectrolyte-based film design in a single-step process with only one polyelectrolyte. Protons, playing the role of morphogens, are gradually generated from an electrode and diffuse into the environment to induce the chemical transformation of a polyanion into a polyampholyte. Hydrolysed at more than $80 \%$ due to the presence of two citraconamide isomers having different sensitivity to the local $\mathrm{pH}$, the polyampholyte generated in situ adsorbs on the substrate and complexes with himself. Resulting films are extremely smooth with thicknesses going to several hundred nanometers after one hour of $-100 \mu \mathrm{A}$ of current application. Thicknesses can easily be tuned by varying the application time of the intensity. Robust polyampholyte based films can be obtained after thermal crosslinking.

T.G. and N.T.T.C thank icFRC and USIAS respectively, for granting postdoctoral fellowships. A.D. thanks the French ministry of research for granting doctoral fellowship. This research was supported by grants from icFRC, IUF and ANR (project “Morphobuildup” ANR-13-JS08-0003-01).

\section{Notes and references}

1 G. Decher, Science, 1997, 277, 1232-1237.

2 C. de Saint-Aubin, J. Hemmerlé, F. Boulmedais, M. F. Vallat, M. Nardin and P. Schaaf, Langmuir, 2012, 28, 8681-8691.

3 D. Mertz, C. J. Ochs, Z. Y. Zhu, L. Lee, S. N. Guntari, G. K. Such, T. K. Goh, L. A. Connal, A. Blencowe, G. G. Qiao and F. Caruso, Chem. Commun., 2011, 47, 12601-12603.

4 (a) S. E. Millar, J. Invest. Dermatol., 2002, 118, 216-225; (b) J. D. Potter, Nat. Rev. Cancer, 2007, 7, 464-474.

5 G. Rydzek, L. Jierry, A. Parat, J. S. Thomann, J.-C. Voegel, B. Senger, J. Hemmerlé, A. Ponche, B. Frisch, P. Schaaf and F. Boulmedais, Angew. Chem. Int. Edit., 2011, 50, 4374-4377.

6 (a) G. Rydzek, T. Garnier, P. Schaaf, J.-C. Voegel, B. Senger, B. Frisch, Y. Haikel, C. Petit, G. Schlatter, L. Jierry and F. Boulmedais, Langmuir, 2013, 29, 10776-10784; (b) G. Rydzek, A. Parat, P. Polavarapu, C. Baehr, J.-C. Voegel, J. Hemmerlé, B. Senger, B. Frisch, P. Schaaf, L. Jierry and F. Boulmedais, Soft Matter, 2012, 8, 446-453; (c) G. Rydzek, P. Polavarapu, C. Rios, J. N. Tisserant, J.-C. Voegel, B. Senger, P. Lavalle, B. Frisch, P. Schaaf, F. Boulmedais and L. Jierry, Soft Matter, 2012, 8, 10336-10343.

7 G. Rydzek, K. Qingmin, M. Li, P. Schaaf, J. P. Hill, F. Boulmedais and K. Ariga, Nano Today, 2015, DOI: 10.1016/j.nantod.2015.1002.1008.

8 (a) F. Beck, Electrochim. Acta, 1988, 33, 839-850; (b) I. Krylova, Prog. Org. Coat. , 2001, 42, 119-131.

9 L. Q. Wu, A. P. Gadre, H. M. Yi, M. J. Kastantin, G. W. Rubloff, W. E. Bentley, G. F. Payne and R. Ghodssi, Langmuir, 2002, 18, 8620-8625. 10 A. J. Kirby and P. W. Lancaster, J. Chem. Soc. Perkin Trans., 1972, 2, 1206-1214.

11 M. F. Aldersley, A. J. Kirby, P. W. Lancaster, R. S. MacDonald and C. R. Smith, J. Chem. Soc., Perkin Trans., 1974, 2, 1487.

12 P. K. Glasoe and F. A. Long, J. Phys. Chem., 1960, 64, 188-190. 13 X. H. Liu, J. T. Zhang and D. M. Lynn, Soft Matter, 2008, 4, 16881695.

14 E. K. Johnson, D. J. Adams and P. J. Cameron, J. Am. Chem. Soc., 2010, 132, 5130-5136.

15 J. J. Harris, P. M. DeRose and M. L. Bruening, J. Am. Chem. Soc., 1999, 121, 1978-1979. 


\section{Table of Contents}

Polyampholyte-based films can be efficiently self-assembled onto a surface in a one-pot manner by using a charge-shifting polyelectrolyte transformed into a polyampholyte by an electrogenerated gradient of protons.

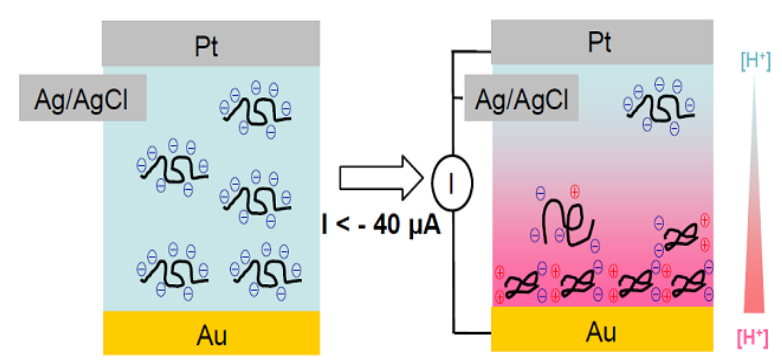

